\title{
AN OPTIMAL DESIGN OF SINGLE TUNED FILTER IN DISTRIBUTION SYSTEMS
}

\author{
A.A. Abou EL-Ela ${ }^{*} \quad$ S. Allam ${ }^{*} \quad$ H. El-Arwash ${ }^{* *}$ \\ *Department of Electrical Engineering, Faculty of Engineering, Shebin-El-Kom \\ ** Egyptian Electrical Transmission Co., Canal Zone-High voltage sector
}

\begin{abstract}
This paper proposes an optimal design of single tuned shunt passive filter for the Underground Ramsis Metro Substation (URMS) using Linear Programming technique as a conventional technique and fuzzy linear programming (FLP) technique as a modern technique. The optimal filter parameters are obtained to overcome the harmonics generated in the voltage and current waveforms, due to the non-linear characteristics of the rectifiers, which distort the voltage and currents waveforms at the point of common coupling (PCC). The harmonic levels are analyzed at different loading conditions using the Fast Fourier Transform (FFT) on MATLAB optimization program. The proposed optimal design of harmonic filter is based on minimizing the cost of the filter parameters and its losses. Both techniques are applied on the system under study. From the results, the THD levels of the line current and the bus voltage are reduced to be within the standard limits. A comparison between the optimal design filters ane carried out using the LP and FLP techniques. However, the lowest cost of filter is obtained using the FLP technique.

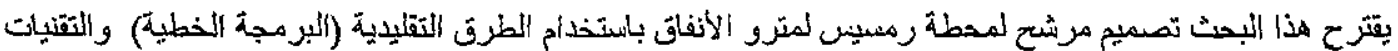

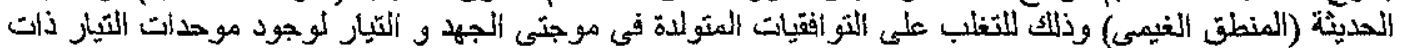

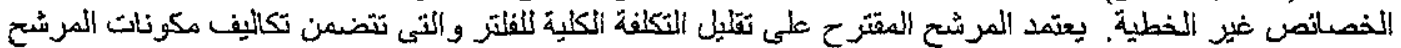

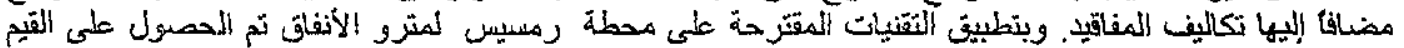

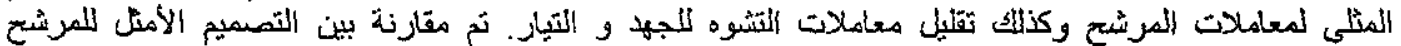

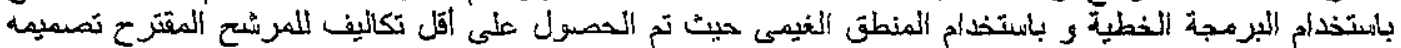

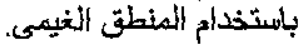

Keywords: Diesel generating unit, optimal PI control, fuzzy logic control, augmented fuzzy control.

\section{INTRODUCTION}

The widespread applications of electronically controlled loads have increased harmonic distortion in power system voltage and current waveforms [14]. Hence, voltage and current waveforms of a distribution or transmission system are usually not pure sinusoids; they may consist of a combination of the fundamental, harmonics and other frequencies caused by transients. The presence of harmonics in the network causes many problems to the customers, starting with home appliances to interfacing with communication equipment and temperature rise in all connected electrical elements. To make the network more reliable and secure, standards of power quality are applied in many distribution networks, and limits are designed for total harmonic distortion (THD). Therefore, the filters are used to control harmonics in the network. To design such filters, it is necessary to:
1. Evaluate the harmonic distortion in both current and voltage waveforms.

2. Have an accurate method of determining filter parameters.

Ref. [5] presented the design of harmonic filter which is based on minimizing the network total apparent power for non-linear loads. However, a non-linear load was considered and its apparent power is obtained. The value of inductance and the resistance was obtained by assuming that the quality factor is equal to 100 for simplicity. In Ref. [6], the author developed a technique to optimize the design for single tuned filter, the filter mathematical model was obtained considering the filter cost and losses as a function of quality factor. The optimum quality factor was used as the basis for defining the filter parameters. The developed technique was applied to design a passive filter for two factories. The decision theory was applied to jointly select the cable and 
filter size under uncertainty due to the presence of non-linear loads [7]. The problem of the cable design and harmonic filter was approached in an integrated way provided that the presence of the filter could affect the sizing of the cable. However, the harmonic currents flowing in the cable are modified by the filter presence with consequent variation of the cable joule loss cost. The objective function is the total cost which is the sum of the cost function of both the cable and the filter. The implementation and practical application of the sizing procedures were discussed and compared in some case studies.

In this paper the decision theory is applied to select the optimal filter size under uncertainty which minimizes the total cost of the filter due to the presence of harmonics in Underground Ramsis Metro Substation (URMS). . The use of the optimization techniques has been important to design the harmonic suppression filter. The minimum total costs of the filter and optimal filter parameters are some areas in which these techniques have been extensively used.

\section{PROBLEM FORMULATION}

Minimization of total costs of the filter (objective function) subject to certain values of filter parameters (constraints) is the biggest challenge for filter design. Conventional methods such as Linear Programming technique (LP) and modern techniques like Fuzzy Linear Programming techniques (FLP) will be used to design the single tuned shunt passive filter optimized for

minimizing the total cost of filter that penetrate the harmonics. An optimization process can be defined as a maximization (or minimization) of an objective function, $f(x)$, subject to some constraints of the problem, $g(x)$. These constraints define the feasible region, i.e. a region that contains possible solutions of the problem.

The objective function is to minimize the total cost of the filter; and can be formulated as:

$$
\operatorname{Min} \mathbf{F}=f\left(R, X_{C}, X_{L}\right)
$$

subject to some constraints which can be formulated as

- Quality factor constraints

$$
Q^{\min } \leq Q \leq Q^{\max }
$$

- Resonant constraints

$$
X_{0}^{\min } \leq X_{0} \leq X_{0}^{\max }
$$

- Filter parameter constraints

$$
\begin{aligned}
& X_{c}^{\min } \leq X_{c} \leq X_{c}^{\max } \\
& X_{L}^{{ }_{\text {min }}} \leq X_{L} \leq X_{L}^{\max } \\
& R^{\min } \leq R \leq R^{\max }
\end{aligned}
$$

$X_{C}$ : is the fundamental frequency capacitive reactance;

$X_{L}$ : is the fundamental frequency inductive reactance;

$Q:$ is the quality factor;

$X_{0}:$ is the resonant reactance;

$\min$ and $\max$ : denote the minimum and the maximum limits respectively.

\section{OPTIMAL PROPOSED FULTER DESIGN (OPFD)}

The problem of filter designi is started from the limit that two or more harmonic components are generated in the voltage and current waves due to the non-linear characteristics of the rectifiers. For optimal filter parameters, the objective function is to minimize the total cost of Eqn. (1). The control variable of the single tuned shunt passive filter design problem is the quality factor, while the dependant variables are the filter parameters $\left(R, X_{\mathrm{C}}, X_{L}\right)$ and the resonant reactance.

3.1 OPFD using Linear Programming (LP) Optimization Technique

The use of conventional LP technique has the popular one may use due to the simplicity of system modeling and objectives. The quality factor determines how sharply the filter is tuned to the target harmonic order. The admittance of a high $Q$ filter drops off quickly at frequencies above and below its target value. The optimal $Q$ for single tuned filter leads to have the lowest harmonic voltage distortion.

The total filter costs are the sum of filter cost and power losses cost. The definition of each item of filter objective function is calculated as follows:

The impedance of single tuned filter $(Z)$ can be expressed as:

$Z=R+j\left(\omega L-\frac{1}{\omega C}\right)$

At the target harmonic order, the filter reactance is:

$X_{0}=h * X_{L}=\frac{X_{C}}{h}=\sqrt{\frac{L}{C}}$

And $Q=\frac{X_{0}}{R}$

where

$h:$ the target harmonic order

The total filter costs objective function of filter design of Eqn. (1) can be expressed as:

$$
C=K_{1} R+K_{2} X_{C}+K_{3} X_{L}
$$

$\mathbf{F}:$ is the total filter cost;

$R:$ is the filter resistance; 
Where

$$
\begin{aligned}
& K_{1}=U_{P} * 10^{3}\left[I_{f}^{2}+\sum_{h=2}^{n} I_{h}^{2}\right] ; \\
& K_{2}=\left(U_{P} K+U_{C}\right)\left[I_{f}^{2}+\sum_{h=2}^{n} \frac{I_{h}^{2}}{h}\right] ; \\
& K_{3}=\left(U_{P} K+U_{L}\right)\left[I_{f}^{2}+\sum_{h=2}^{n} I_{h}^{2} * h\right]
\end{aligned}
$$

$U_{C}:$ is the incremental cost of the capacitor and it is equal to $170 * 10^{3}$ LE/MVAR

$U_{L}$ : is the incremental cost of the reactor and it is equal to $170 * 10^{3} \quad$ LE/MVAR

$\mathrm{n}:$ is the harmonic number

\subsection{OPFD using Fuzzy Linear Programming (FLP)}

Optimization Technique

The Fuzzy Linear Programming (FLP) technique is used to achieve the objective function in Eqn. (1) and satisfy the filter parameters (constraints). The difference between LP and FLP techniques is that the values and operators using the conventional LP are crisp values, while, the values and/or operators of the FLP are Fuzzified characteristics, using FLP technique.

\subsubsection{Fuzzy modeling of constraints:}

The proposed triangular fuzzy modeling for the filter resistance is shown in Fig. 1. It is seen that, a membership function for the resistance is equal to 1 assigned to $R^{\text {med }}$, each component of filter is represented by two linear constraints: the lower limit and the upper limits.

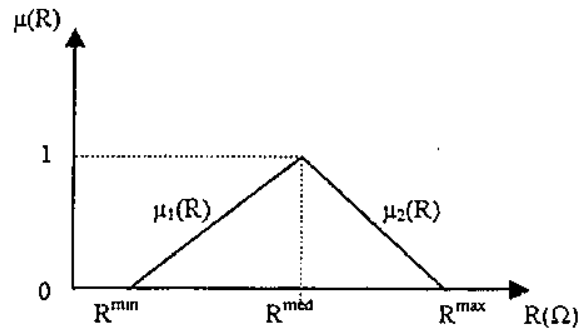

Fig. 1 Triangular fuzzy modeling for the filter resistance

The lower limit membership for the resistance of the filter is described as follow:

$$
\mu(R)= \begin{cases}0 & R<R^{\text {min }} \\ \left(R-R^{\text {min }}\right) /\left(R^{\text {med }}-R^{\text {min }}\right) & R^{\text {min }} \leq R \leq R^{\text {med }} \\ 1 & R>R^{\text {med }}\end{cases}
$$

and the upper resistance limit membership is:

$$
\mu_{2}(R)= \begin{cases}1 & R<R^{\operatorname{med}} \\ \left(R^{\max }-R\right) /\left(R^{\max }-R^{\text {med }}\right) & R^{\bmod } \leq R \leq R^{\max } \\ 0 & R>R^{\max }\end{cases}
$$

Similarly, the proposed triangular fuzzy modeling for the capacitive reactance is shown in Fig. 2

The lower limit membership for the capacitive reactance of the filter is described as follow:

$$
\mu_{3}\left(X_{C}\right)= \begin{cases}0 & X_{c}<X_{C}{ }^{\text {min }} \\ \left(X_{C}-X_{C}{ }^{\text {min }}\right) /\left(X_{C}^{\text {med }}-X_{C}^{\text {min }}\right) & X_{C}{ }^{\text {min }} \leq X_{c} \leq X_{C}{ }^{\text {med }} \\ 1 & X_{C}>X_{C}{ }^{\text {med }}\end{cases}
$$

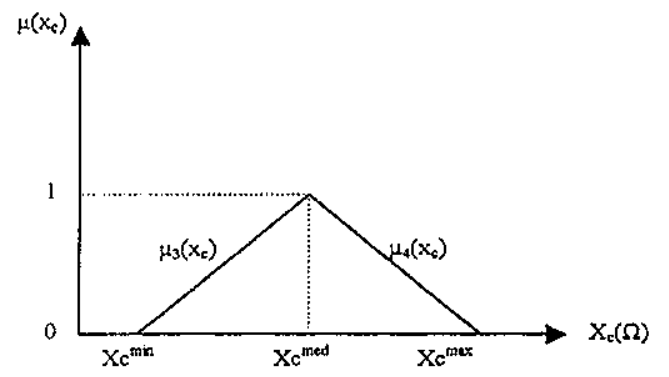

Fig. 2 Triangular fuzzy modeling for the filter capacitive reactance

The upper capacitive reactance limit membership is:

$$
H_{4}\left(X_{C}\right)= \begin{cases}1 & X_{C}<X_{C}^{\text {med }} \\ \left(X_{C}^{\max }-X_{C}\right) /\left(X_{C}^{\max }-X_{C}^{\text {med }}\right) & X_{C}^{{ }^{\text {med }}} \leq X_{C} \leq X_{C}^{\max } \\ 0 & X_{C}>X_{C}^{\max }\end{cases}
$$

Similarly, the proposed triangular fuzzy modeling for the inductive reactance is shown in Fig. 3.

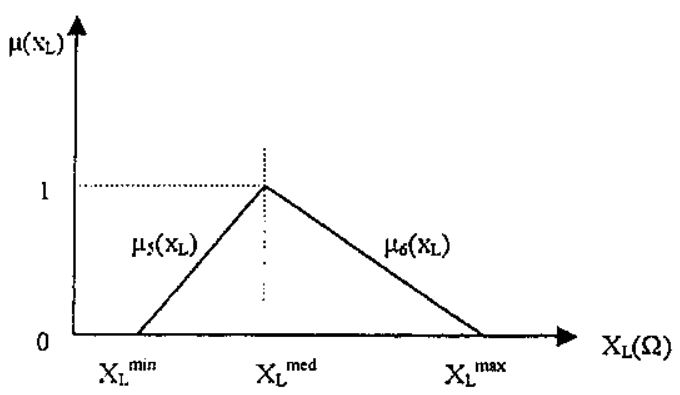

Fig. 3 Triangular fuzzy modeling for the filter inductive reactance

The lower limit membership for the inductive reactance of the filter is described as follow:

$$
\mu_{S}\left(X_{L}\right)= \begin{cases}0 & X_{L}<X_{L}^{\text {min }} \\ \left(X_{L}-X_{L}^{\text {min }}\right) /\left(X_{L}^{\text {med }}-X_{L}^{\text {min }}\right) & X_{L}^{\text {min }} \leq X_{L} \leq X_{L}^{\text {med }} \\ 1 & X_{L}>X_{L}^{\text {med }}\end{cases}
$$

and the upper inductive reactance limit membership is:

$$
H_{8}\left(X_{L}\right)= \begin{cases}1 & X_{L}<X_{L}^{\text {med }} \\ \left(X_{L}^{\max }-X_{L}\right) /\left(X_{L}^{\max }-X_{L}^{\text {med }}\right) & X_{L}^{\operatorname{med}} \leq X_{L} \leq X_{L}^{\max } \\ 0 & X_{L}>X_{L}^{\max }\end{cases}
$$

Similaraly, the proposed triangular fuzzy modeling for the quality factor can be expressed as in Fig. 4. 


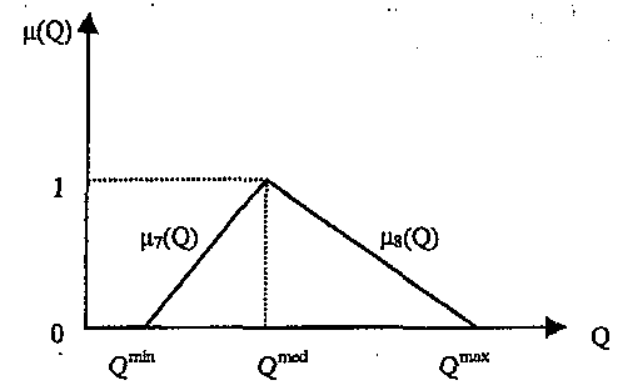

Fig. 4 Triangularfuzzy modeling for the filter quality factor

The lower limit membership for the quality factor of the filter is described as follow:

$\mu_{1}(Q)= \begin{cases}0 & Q<Q^{\text {min }} \\ \left(Q-Q^{\text {min }}\right) /\left(Q^{\text {ned }}-Q^{\text {min }}\right) & Q^{\text {min }} \leq Q \leq Q^{\text {med }} \\ 1 & Q>Q^{\text {med }}\end{cases}$

and the upper quality factor limit membership is:

$\mu_{8}(Q)= \begin{cases}1 & Q<Q^{\operatorname{med}} \\ \left(Q^{\max }-Q\right) /\left(Q^{\max }-Q^{m e d}\right) & Q^{\operatorname{med}} \leq Q \leq Q^{\max } \\ 0^{\cdots} & Q>Q^{\max }\end{cases}$

\subsubsection{Proposed fuzzy modeling of objective} function:

The objective function, minimizes the total filter costs as much as possible. The proposed fuzzy modeling of the total costs function is shown in Fig. 5. The fuzzy membership function of the costs, is described as:

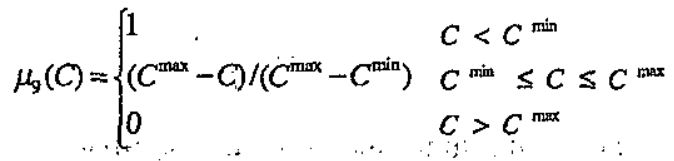

where, $C^{\min }$ and $C^{\max }$ are the minimum and the maximum total filter cost.

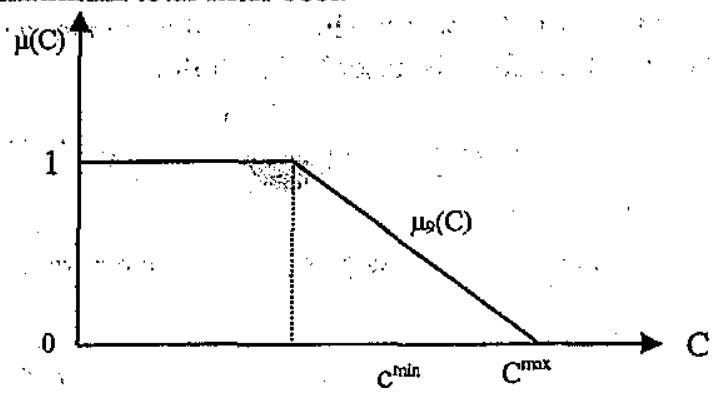

Fig. 5 Fuzzy modeling for the filter total costs

The calculations of the optimal filter parameters are implemented in the design of single tuned shunt passive filter limbs in order to provide the following:

- Minimize the harmonics in the source current.

- Minimize the total filter costs at the optimal quality factor.

\section{APPLICATIONS}

\subsection{System Description}

In this paper, number of optimal passive filters is designed for URMS, each of them may be used for improving the power quality of the URMS. The optimal filters are designed using the conventional and the modern techniques.

In the Appindex Figure A-1 shows the URMS system. However, the data of the considered substation is given in Table A-1 [5]. Ramsis substation consists of three power transformers, 3phase, $\mathrm{Y} / \mathrm{Y} / \Delta$ with tertiary winding. Each transformer is rated $220 / 20 / 20 \mathrm{KV}$ and $36 \mathrm{MVA}$.

This substation is fed from the $220 \mathrm{KV}$ system : via:

1) One feeder coming from Shubra El-Khima station

2) One feeder coming from Cairo East station.

3) One feeder coming from Sabtia substation.

The Ramsis substation has six load buses; four buses (TB1-TB4) are used as traction buses, and two buses (LB1and LB2) are used for providing the lighting loads, air conditioning loads,etc.

The traction buses TB1-TB4 supply a number of traction buses which are $8,7,9$ and 9 rectifier stations, respectively. Each rectifier station is rated at $20 \mathrm{KV}$ as an input voltage, $1500 \mathrm{~V}$ output voltage and $3 \mathrm{MW}$ output power.

Table 1 shows the harmonic contents of the voltage and current at TB4 for different loading conditions. Figure 6 shows the full load voltage and current waveforms and their harmonic analysis without considering the filter.

Table 1 Harmonics content of the voltage and current at the busTB4 for different loading conditions.

\begin{tabular}{|c|c|c|c|}
\hline $\begin{array}{c}\text { Loading } \\
\text { conditions }\end{array}$ & $\begin{array}{c}\text { Harmonic } \\
\text { order }\end{array}$ & Voltage, V & Current, A \\
\hline \multirow{3}{*}{ Light load } & $1^{3 t}$ & $10585 \leq-10$ & $130 \angle 6.5$ \\
\hline & $11^{\text {th }}$ & $560<47.3$ & $23 \angle-203$ \\
\hline & $13^{\text {th }}$ & $673<-26$ & $22 \angle-272$ \\
\hline \multirow{3}{*}{ Half load } & $1^{\text {st }}$ & $10417 \angle-12$ & $259 \angle-16$ \\
\hline & $11^{\text {th }}$ & $1047 \angle-12.3$ & $43 \angle-264$ \\
\hline & $13^{\text {th }}$ & $1221<-96.5$ & $41.7 \angle-6.5$ \\
\hline \multirow{3}{*}{ Full load } & $1^{52}$ & $10259 \angle-13$ & $392 \angle-20$ \\
\hline & $11^{43}$ & $1466 \angle-31$ & $61<-284$ \\
\hline & $13^{\mathrm{bh}}$ & $1658<-119$ & $57.4 \angle-7.3$ \\
\hline
\end{tabular}

From Table 1, and Fig. ' 6 ; at the point of common coupling (PCC) at TB4, it can be shown that, both the voltage and current waves are heavily distorted. However, the most dominant harmonics are the $11^{\text {th }}$ and $13^{\text {th }}$ orders and the ratio of harmonic current to the fundamental current is decreased with by $17.5 \%$ and $15 \%$ for the light and full loading conditions, respectively. On the other hand, the magnitude of the 
voltage harmonic is increased with increasing the harmonic order and when the load is increased. The voltage for $13^{\text {th }}$ harmonic order is greater than the voltage for $11^{\text {th }}$ harmonic order due to the higher impedance of the $13^{\text {th }}$ harmonic order.

Now, in order to improve the power quality at (PCC) of traction bus (TB4), a number of optimal filters are designed and presented in the next section. Each of these filters may be connected individually at the PCC.

\subsection{Results and Comments}

\subsubsection{OPFD using LP Technique}

The URMS system is simulated and analyzed using FFT on MATLAB optimization program.

Table 2 shows the parameters of the OPFD which are connected to bus TB4 at different loading conditions to reduce the total harmonic distortion (THD) levels in the distribution system.

Table 3 shows the THD levels of the voltage and current at bus TB4 with and without the optimal proposed filter for different loading conditions.

Figures 6 displays the voltage and current waveforms as well as their harmonics analysis at the traction bus TB4, without considering the propsed filter, at full loading condition. However, Table 3 shows the THD levels of voltage and current at bus TB4 with and without the OPFD filter AT different loading conditions using LP technique.

Table 2 Optimal filter parameters at different load conditions using $L P$ technique

\begin{tabular}{|c|c|c|c|c|}
\hline $\begin{array}{c}\text { Loading } \\
\text { conditions }\end{array}$ & $\begin{array}{c}\text { Harmonic } \\
\text { order }\end{array}$ & $\mathbf{R}(\boldsymbol{\Omega})$ & $\mathbf{C}(\mu \mathrm{F})$ & $\mathrm{L}(\mathrm{mH})$ \\
\hline \multirow{2}{*}{ Light load } & $11^{\text {th }}$ & 2.5 & 2.89 & 28.96 \\
\cline { 2 - 5 } & $13^{\text {th }}$ & 2.1 & 2.98 & 20.7 \\
\hline \multirow{2}{*}{ Half load } & $11^{\text {th }}$ & 2.5 & 2.98 & 28.96 \\
\cline { 2 - 5 } & $13^{\text {ht }}$ & 2.1 & 2.98 & 20.7 \\
\hline \multirow{2}{*}{ Full load } & $11^{\text {th }}$ & 2.5 & 2.98 & 28.96 \\
\cline { 2 - 5 } & $13^{\text {th }}$ & 2.1 & 2.98 & 20.7 \\
\hline
\end{tabular}

Table 3 Summary of THD levels of bus TBA at different load conditions using LP technique

\begin{tabular}{|c|c|c|c|c|}
\hline \multirow{2}{*}{$\begin{array}{l}\text { Loading } \\
\text { conditions }\end{array}$} & \multicolumn{2}{|c|}{ THD of voltage } & \multicolumn{2}{|c|}{ THD of current } \\
\hline & $\begin{array}{l}\text { Without } \\
\text { filter }\end{array}$ & $\begin{array}{l}\text { With } \\
\text { filter }\end{array}$ & $\begin{array}{l}\text { Without } \\
\text { filter }\end{array}$ & $\begin{array}{l}\text { With } \\
\text { filter }\end{array}$ \\
\hline Light load & 8.3 & 1.268 & 24.8 & 2.18 \\
\hline Half load & 15.5 & 1.23 & 23.3 & 2.21 \\
\hline Full load & 21.6 & 1.312 & 21.5 & 2.23 \\
\hline
\end{tabular}

From Table 3 and Figure 7, it can be shown that:

- The THD levels of the voltage and current waveforms are reduced to be within the standard limits [8] for the OPFD using LP technique.

\subsubsection{OPFD Using FLP Technique}

The calculation of the optimal filter parameters is implemented to design the optimal proposed filters in order to reduce the THD levels and minimize the total filter costs.
Table 4 shows the parameters of the tuned filters which are connected to TB4 at different loading conditions using the Fuzzy Linear Programming Technique. Table 5 shows the THD levels at bus TB4 without and with the OPFD using FLP technique.

Table 4 Optimal filter parameters at different load conditions

\begin{tabular}{|c|c|c|c|c|}
\hline $\begin{array}{c}\text { Loading } \\
\text { conditions }\end{array}$ & $\begin{array}{c}\text { Harmonic } \\
\text { order }\end{array}$ & $\mathbf{R}(\mathbf{\Omega})$ & $\mathbf{C}(\boldsymbol{\mu} \mathbf{F})$ & $\mathbf{L}(\mathbf{m H})$ \\
\hline \multirow{2}{*}{ Light load } & $11^{\text {th }}$ & 2.2 & 2.82 & 29.6 \\
\cline { 2 - 5 } & $13^{\mathrm{L}}$ & 1.8 & 2.82 & 21.32 \\
\hline \multirow{2}{*}{ Half load } & $11^{\text {Lh }}$ & 2.3 & 2.84 & 29.6 \\
\cline { 2 - 5 } & $13^{\text {th }}$ & 1.9 & 2.84 & 21 \\
\hline \multirow{2}{*}{ Full load } & $11^{\text {th }}$ & 2.4 & 2.857 & 29.28 \\
\cline { 2 - 5 } & $13^{\text {th }}$ & 2 & 2.857 & 21 \\
\hline
\end{tabular}

Table 5 Summary of THD of TB4 at different load conditions using FLP technique

\begin{tabular}{|c|c|c|c|c|}
\hline \multirow{2}{*}{$\begin{array}{c}\text { Loading } \\
\text { conditions }\end{array}$} & \multicolumn{2}{|c|}{ THD of voltage } & \multicolumn{2}{c|}{ THD of current } \\
\cline { 2 - 5 } & $\begin{array}{c}\text { Without } \\
\text { filter }\end{array}$ & $\begin{array}{c}\text { With } \\
\text { filter }\end{array}$ & $\begin{array}{c}\text { Without } \\
\text { filter }\end{array}$ & $\begin{array}{c}\text { With } \\
\text { filter }\end{array}$ \\
\hline Light load & 8.3 & 1.18 & 24.8 & 2.04 \\
\hline Half load & 15.5 & 1.2 & 23.3 & 2.14 \\
\hline Full load & 21.6 & 1.22 & 21.5 & 2.2 \\
\hline
\end{tabular}

From Table 5, the THD levels are decreased with the OPFD using FLP technique compared with Table 4.

Figure 8 displays the voltage and current waveforms using FLP at full load condition, respectively.

Tabies 6 and 7 show the quality factor and the total costs of the OPFD using LP and FLP techniques at different loading conditions, respectively.

Table 6 Optimal filter quality factors at different load conditions using LP\& FLP techniques

\begin{tabular}{|c|c|c|c|c|c|c|}
\hline \multirow{2}{*}{ Technique } & \multicolumn{2}{|c|}{$\begin{array}{c}\text { Quality } \\
\text { Factor at } \\
\text { Light Load }\end{array}$} & \multicolumn{2}{|c|}{$\begin{array}{c}\text { Quality } \\
\text { Factor at } \\
\text { Half Load }\end{array}$} & \multicolumn{2}{|c|}{$\begin{array}{c}\text { Quality } \\
\text { Factor at } \\
\text { Full load }\end{array}$} \\
\cline { 2 - 7 } & $\mathbf{1 1}^{\text {th }}$ & $\mathbf{1 3}^{\text {th }}$ & $\mathbf{1 1}^{\text {th }}$ & $\mathbf{1 3}^{\text {th }}$ & $\mathbf{1 1}^{\text {th }}$ & $13^{\text {th }}$ \\
\hline $\begin{array}{c}\text { With LP } \\
\text { filter }\end{array}$ & 40 & 40 & 40 & 40 & 40 & 40 \\
\hline $\begin{array}{c}\text { With FLP } \\
\text { filter }\end{array}$ & 48.03 & 55.91 & 36.12 & 39.17 & 36.0 & 38.68 \\
\hline
\end{tabular}

Table 7 Total costs of the optimal proposed filter at different load conditions using LP\&FLP Techniques

\begin{tabular}{|c|c|c|c|c|c|c|}
\hline \multirow[t]{2}{*}{ Tech. } & \multicolumn{2}{|c|}{$\begin{array}{l}\text { Total cost } \\
* 10^{6}(\mathrm{LE}) \text { at } \\
\text { light load }\end{array}$} & \multicolumn{2}{|c|}{$\begin{array}{c}\text { Total cost } * 10^{6} \\
\text { (LE) at half } \\
\text { load }\end{array}$} & \multicolumn{2}{|c|}{$\begin{array}{c}\text { Total cost*10 } \\
\text { (LE) at full } \\
\text { load }\end{array}$} \\
\hline & $11^{\text {th }}$ & $13^{\text {th }}$ & $11^{\text {th }}$ & $13^{\text {th }}$ & $11^{\text {th }}$ & $13^{\text {th }}$ \\
\hline $\begin{array}{l}\text { With } \\
\text { LP } \\
\text { filter }\end{array}$ & 4.173 & 4.0348 & 16.63 & 15.995 & 37.768 & 36.535 \\
\hline $\begin{array}{l}\text { With } \\
\text { FLP } \\
\text { filter }\end{array}$ & 4.151 & 4.0137 & 16.528 & 15.985 & 37.766 & 36.534 \\
\hline
\end{tabular}

From Table 6, the quality factor has a fixed value when the filter is designed using LP technique because the output values of this technique are crisp 
values. While, the quality factor has various values using FLP technique because this technique results has fuzzification values. However, the Fuzzification values are adjustment closed to the standard values for the filter parameters.

From Table 7 , the total costs of filter designed by FLP technique are smaller than that designed by LP technique for different harmonic orders.

\section{CONCLUSION}

In this paper, the single tuned shunt passive filter has been designed for URMS at different loading conditions using the LP and FLP techniques.

Both techniques thave been successfully applied to obtain the optimal filter parameters which minimize the total filter cost. However, the Total Harmonic Distortion (THD) is minimized to be within the standard limits, and has prevented all the characteristic harmonic orders. A minimum total 'costs of filter has been obtained using FLP technique compared with the LP technique. Also, the optimal values of the quality factor and the optimal filter parameters have been efficiently computed

\section{REFERENCES}

[1] S. B. Davan and A. Straughen, "Power Semiconductor Circuits", John Wiley \& Sons, 1985, New York.

[2] J. Arrilalaga, D. A.Bradley, and P. S. Bodger, "Power System Harmonics", John Wiley\& Sons, 1985, New York.

[3] J.F. Fuller, E. F. Fuchs, and D. J. Roesler, - "Influence of Harmonics on Power Distribution "System Protection", IEEE Transactions on Power Delivery, Vol. PWRD-3, no. 2, April 1988, pp. 549-57.

[4] IEEE Working Group on Power System Harmonics, "Power System Harmonics: An Overview", IEEE Transaction on Power Delivery, vol. PAS-102, no. 8, August 1983, pp. 2455-2459.

[5] Somaya A. M. Shehata, Hamdy S. Khalil, Sameh K. Mena, "Harmonic analysis and filter design for the underground Graeter Cairo Metro", MEPCON'2000, March $28-30,2000$, pp 317321.

[6] G. Carpinelli, P.Caramia, A. Russo and P. Verde, ${ }^{\text {n }}$ Decission Theory Criteria for Sizing Cable and Harmonic Filters in Distribution Systems", UPEC" 2004, England, 2004.

[7] Mamdouh A. El-Aziz, E. El-Din Abou El-Zahab and G. A. Abdel Salam, "New Techniques of the Passive Filter Design in Industrial Applications: A- Case Study", MEPCON'2003, December 16-18, 2003, pp 317-321.

[8] IEEE Recommended practices And Requirements For Harmonic Control In Power Systems, IEEE Standard 519/1992.
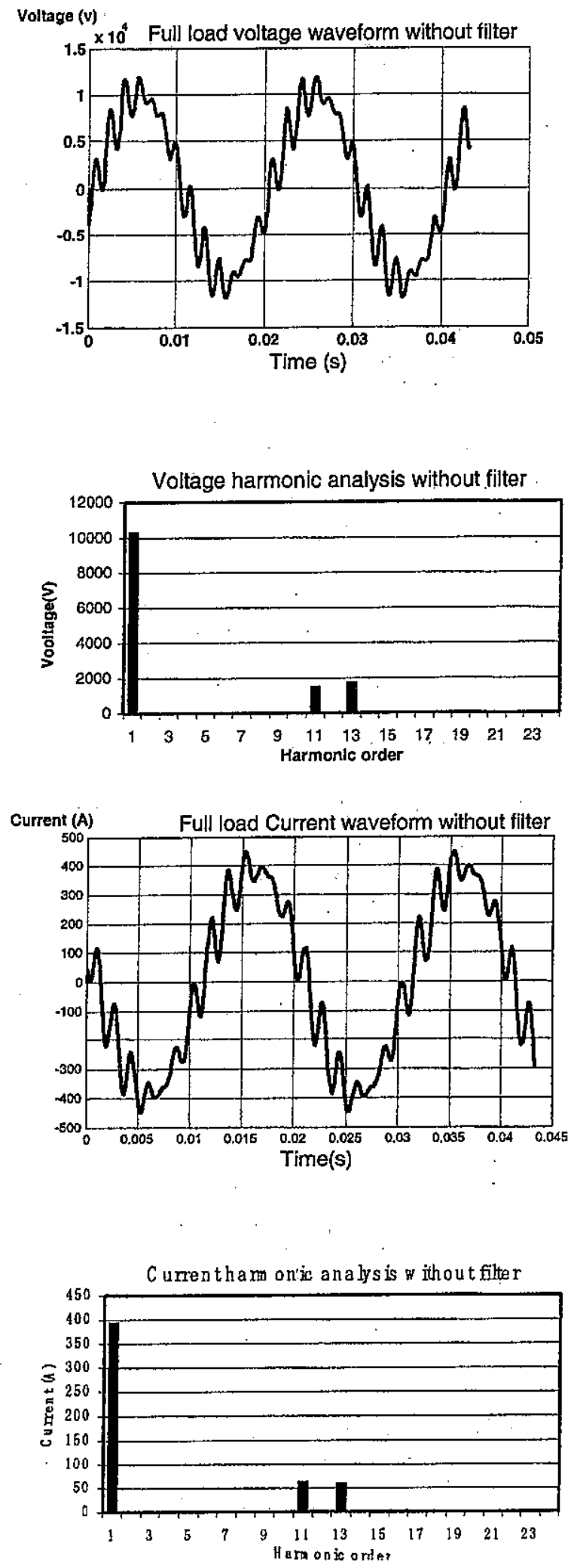

Fig. 6 Full load voltage and current waveforms of TB4 at PCC and its harmonic analysis without filter 


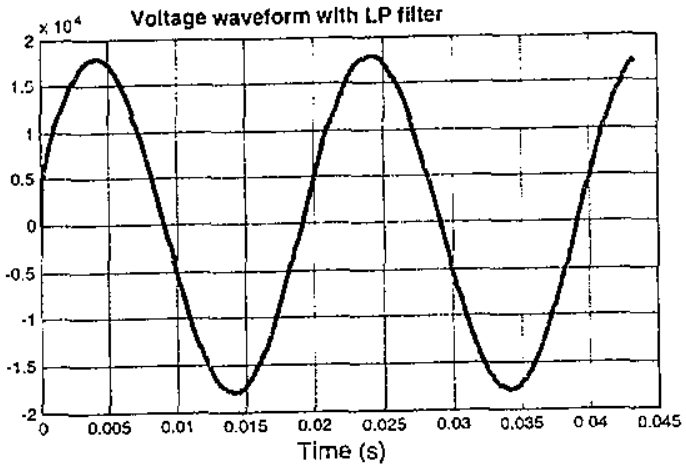

\section{APPENDIX}

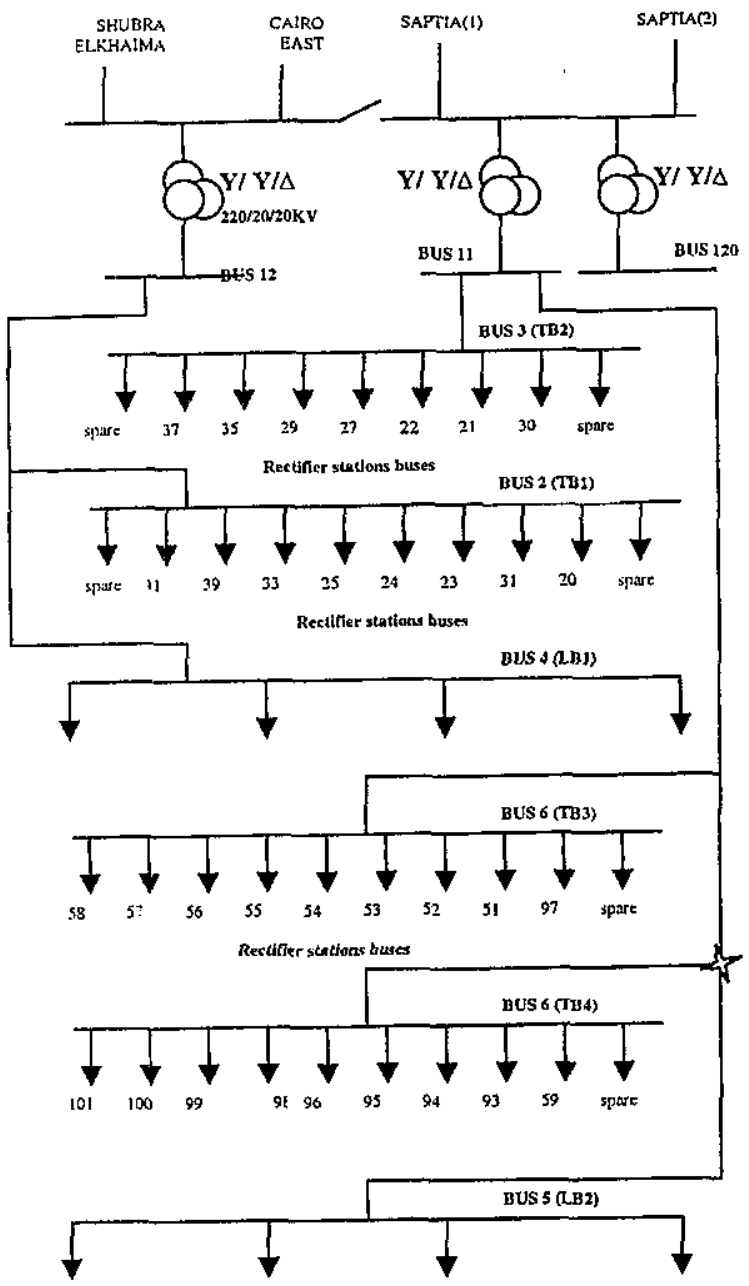

Fig. A.1 Single line diagram of RSM

1. All lines are $20 \mathrm{kv}$ underground cables with the following parameters:

Resistance $=0.22667 \Omega / \mathrm{km}$.

Series reactance (at $50 \mathrm{~Hz}$ ) $=0.113 \Omega / \mathrm{km}$.

Shunt capacitance (at $50 \mathrm{~Hz}$ ) $=2000 \Omega / \mathrm{km}$.

2. Transformers are rated at $220 / 20 / 20 \mathrm{kv}, 36$ MVA. They have the following parameters:

Short circuit reactance $X_{p s}=X_{p t}=16.8 \Omega$

Short circuit resistance $\mathrm{R}_{\mathrm{ps}}=\mathrm{R}_{\mathrm{pt}}=8.34 \Omega$

Fig. 8 Full load voltage and current waveforms of TB4 at PCC with FLP filter 
Table A.1 The data of Underground Ramsis Substation Metro (URMS)

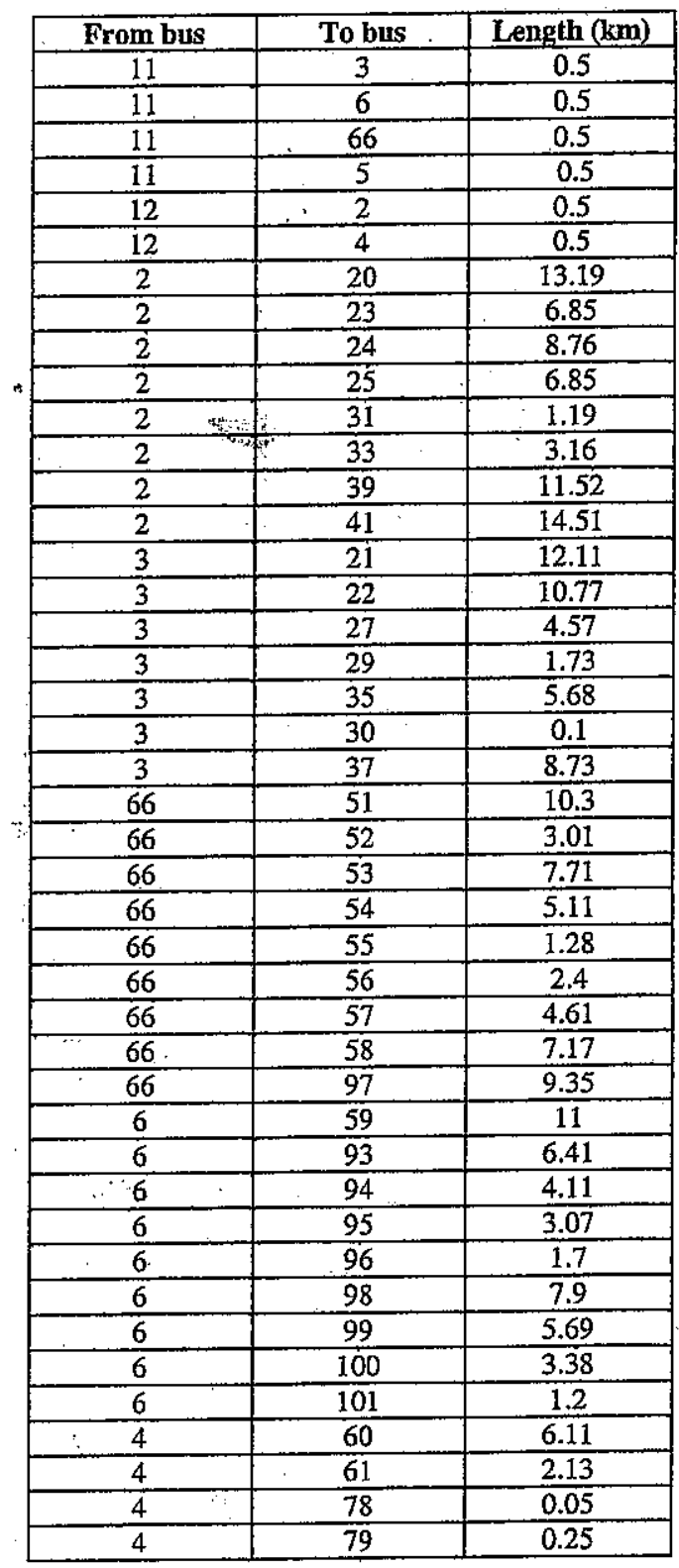

